\title{
Acknowledgement to Reviewers of Recycling in 2016
}

\author{
Recycling Editorial Office, \\ Published: 11 January 2017 \\ MDPI AG, St. Alban-Anlage 66, 4052 Basel, Switzerland; recycling@mdpi.com
}

The editors of Recycling would like to express their sincere gratitude to the following reviewers for assessing manuscripts in 2016.

We greatly appreciate the contribution of expert reviewers, which is crucial to the journal's editorial process. We aim to recognize reviewer contributions through several mechanisms, of which the annual publication of reviewer names is one. Reviewers receive a voucher entitling them to a discount on their next MDPI publication and can download a certificate of recognition directly from our submission system. Additionally, reviewers can sign up to the service Publons (https://publons.com) to receive recognition. Of course, in these initiatives we are careful not to compromise reviewer confidentiality. Many reviewers see their work as a voluntary and often unseen part of their role as researchers. We are grateful to the time reviewers donate to our journals and the contribution they make.

If you are interested in becoming a reviewer for Recycling, see the link at the bottom of the webpage http://www.mdpi.com/reviewers.

The following reviewed for Recycling in 2016:

Bank, Lawrence C.
Beutel, Joerg
Bohutskyi, Pavlo
Castro Gomes, João
Cheng, Haitao
Chia, Aaron
Corder, Glen
Da Costa Lopes, André M.
D'Adamo, Idiano
Dawson, Richard
Delogu, Massimo
Demers, Isabelle
Di Maria, Francesco
Dyer, Tom
Fernandes, Hugo
Fiorillo, Damiano
Godoy, Alex
Goldmann, Daniel
Golev, Artem
Guido, Grause

Hae Choi, Young
Hettiarachchi, Hiroshan
Horttanainen, Mika
Hotta, Yasuhiko
Houng, Harvey J.
Inazumi, Shinya
Jayaraman, Krishnan
Keramitsoglou, Kiriaki M.
Kim, Junbeum
Kruopienė, Jolita
La Mantia, Francesco P.
Li, Hui
Menikpura, Nirmala
Merkisz-Guranowska, A.
Moll, Henri C.
Nowak, Thomas
Numata, Daisuke
Patrício, João
Piippo, Sari
Pretz, Thomas

Ribeiro, Maria C. S.

Santulli, Carlo

Sarris, Dimitris

Solís-Guzmán, Jaime

Strube, Jochen

Svecova, Lenka

Tonjes, David J.

Tudor, Terry

Urreaga, J. Martínez

White, Philip

Wilts, Henning

Withers, Paul J. A.

Woodley, Alan

Ylä-Mella, Jenni

Yousif, Belal

Zaman, Atiq Uz

Zeng, Xianlai

Zurbrügg, Christian

(C) 2017 by the authors; licensee MDPI, Basel, Switzerland. This article is an open access article distributed under the terms and conditions of the Creative Commons Attribution (CC-BY) license (http://creativecommons.org/licenses/by/4.0/). 